View Point

\title{
Can Rabies Vaccines be given with or after COVID- 19 Vaccines and Vice Versa?
}

\author{
Omesh Kumar Bharti', Jugal Kishore ${ }^{2}$ \\ ${ }^{1}$ State Epidemiologist from Shimla, Himachal Pradesh, India. \\ ${ }^{2}$ Director Professor \& Head Department of Community Medicine, VMMC \& SJH, New Delhi. \\ DOI: https://doi.org/10.24321/2455.7048.202103
}

\section{I $\quad \mathbf{N} \quad \mathbf{F} \quad \mathbf{O}$}

\author{
Corresponding Author: \\ Omesh Kumar Bharti, State Epidemiologist from \\ Shimla, Himachal Pradesh, India. \\ E-mail Id: \\ bhartiomesh@gmail.com \\ Orcid Id: \\ https://orcid.org/0000-0001-5178-1503 \\ How to cite this article: \\ Bharti OK, Kishore J. Can Rabies Vaccines be \\ given with or after COVID-19 Vaccines and Vice \\ Versa?. Epidem Int. 2021;6(2):4-5.
}

Date of Submission: 2021-06-04

Date of Acceptance: 2021-06-25
Rabies is a dreaded disease and kills about $59,000^{1}$ persons every year. The ongoing COVID-19 pandemic has also killed about 3.9 million $^{2}$ people since it started last year in 2020. The recent fast track development of vaccines against COVID-19 has emerged as a hope to contain the pandemic. Questions are being asked about whether one can take rabies vaccine with or after COVID-19 vaccination and vice versa. Rabies is caused by a single-stranded RNA virus belonging to Lyssavirus genus of the family Rhabdoviridae. These viruses are enveloped and have a single-stranded RNA genome with negative-sense and cause neurological symptoms and encephalitis. The Severe Acute Respiratory Syndrome Coronavirus-2 (SARS-CoV-2) is a positive-sense, single-stranded RNA virus that causes the potentially lethal COVID-19 respiratory tract infection. This new SARS-CoV-2 virus belongs to the genus Betacoronavirus, which also includes Severe Acute Respiratory Syndrome Coronavirus (SARSCoV-1) and Middle East Respiratory Syndrome Coronavirus (MERS-CoV). The doctors fear any adverse cross-reaction between the two vaccines because both rabies and COVID-19 viruses are RNA viruses.

It is natural that people getting COVID-19 vaccine shots are coming to the clinics for rabies vaccination or people who had an appointment for COVID-19 vaccine shots are being bitten by animals and are reporting for rabies vaccination to the clinics. Doctors are trying hard to know if they can vaccinate people with rabies vaccine after COVID-19 shots and vice versa. There are no clear cut guidelines on this and we need real-life experience to answer the question as COVID-19 vaccine companies are non-committal on interaction with other vaccines. Let's discuss some of the real-life situations and outcomes.

A 70-year-old doctor called saying that he was bitten by a cat and had his second dose of COVID-19 vaccine the next day. He wanted to know what should he do in such a situation. We advised him to defer COVID-19 vaccine for 7 days and take 3 doses of rabies vaccination (RV), as per the schedule, on the $0,3 \mathrm{rd}$, and 7 th days along with wound infiltration with Equine Rabies Immunoglobulins (ERIG). ${ }^{3} \mathrm{He}$ did the same and is fine.

A 53-year-old lady was bitten by a street dog and had taken one dose of COVID-19 vaccine seven days back. She was administered rabies vaccine as per the schedule and later she took the second dose of CVID- 
19 vaccine as scheduled, and was perfect after that. Many patients in our Anti-Rabies Clinic and Research Centre at DDU hospital, Shimla, Himachal Pradesh, are coming for rabies Post Exposure Prophylaxis (PEP) having one or two shots of COVID-19 vaccination. In three weeks, we have given rabies PEP to 42 patients who had one or two shots of Covishield and found no adverse event with any of the two vaccines.

APCRI journal, Jan 2021 Issue has reported a case study of a 46-year-old male who had a dog bite and had come for PEP shots. He was looking sick so was asked to get his COVID-19 test done and later he was found to be COVID-19 positive, but antibodies tested were positive for both rabies and COVID-19. ${ }^{4}$

MERS vaccine has been in a developmental stage on the rabies virus platform and initial findings indicate that $R V \Delta \mathrm{P}$ MERS/S1 is a promising and safe bivalent-vaccine candidate against both MERS-CoV and RV. ${ }^{5}$ CORAVAX, a COVID-19 vaccine is being made on the rabies vaccine platform and results show that both a live and an inactivated rabies virus containing the SARS-CoV-2 spike S1 protein induces potent virus-neutralising antibodies at much higher levels than seen in the sera of convalescent patients. ${ }^{6}$ In a new study, bivalent RABV/ ZEBOV vaccines have been described as having several distinct advantages that may speed the development of inactivated vaccines for use in humans and potentially live or inactivated vaccines for use in non-human primates at risk of Ebola (EBOV) infection in endemic areas. ${ }^{7}$

In the case of category III dog bite, besides PEP, Rabies Immunoglobulin (RIG) should be infiltrated at the wound site locally. In the case of an immunocompromised patient, RIG can be infiltrated locally in category II bite also. Based on the available evidence we have and literature review, it is inferred that antibodies to both rabies and SARS viruses are present in people given both antigens simultaneously, and based on our practice, we can say that both vaccines can be administered simultaneously. However, in case of urgent requirement of PEP in dog bite, we can defer COVID-19 vaccine for a week or so as a precaution till more data is available. To conclude, in the case of COVID-19 vaccination you have a choice to defer COVID-19 vaccine for a week or more but we don't have a choice to defer rabies PEP that is required urgently since rabies is $100 \%$ fatal.

\section{Conflict of Interest: None}

\section{References}

1. Hampson K, Coudeville L, Lembo T, Sambo M, Kieffer A, Attlan M, Barrat J, Blanton JD, Briggs DJ, Cleaveland S, Costa P, Freuling CM, Hiby E, Knopf L, Leanes F, Meslin FX, Metlin A, Miranda ME, Muller T, Nel LH, Recuenco S, Rupprecht CE, Schumacher C, Taylor L, Vigilato MA, Zinsstag J, Dushoff J; Global Alliance for Rabies Control
Partners for Rabies Prevention. Estimating the global burden of endemic canine rabies. PLoS Negl Trop Dis. 2015;9(4):e0003709. [PubMed] [Google Scholar]

2. Worldometer [Internet]. Available from: https://www. worldometers.info/coronavirus/

3. Bharti OK, Thakur B, Rao R. Wound-only injection of rabies immunoglobulin (RIG) saves lives and costs less than a dollar per patient by "pooling strategy". Vaccine. 2019;37(Suppl 1): A128-A131. [PubMed] [Google Scholar]

4. Poddar S, Mukherjee D, Roy R. Anti rabies vaccination in presence of COVID-19 affected patient accidentally associated with HIV infection. APCRI J. 2021;22(2):71-4.

5. Kato H, Takayama-Ito M, lizuka-Shiota I, Fukushi S, Posadas-Herrera G, Horiya M, Satoh M, Yoshikawa T, Yamada S, Harada S, Fujii H, Shibamura M, Inagaki T, Morimoto K, Saijo M, Lim CK. Development of a recombinant replication-deficient rabies virus-based bivalent-vaccine against MERS-CoV and rabies virus and its humoral immunogenicity in mice. PLoS One. 2019 Oct 7;14(10):e0223684. [PubMed] [Google Scholar]

6. Kurup D, Wirblich C, Ramage H, Schnell MJ. Rabies virusbased COVID-19 vaccine CORAVAX ${ }^{\mathrm{TM}}$ induces high levels of neutralizing antibodies against SARS-CoV-2. NPJ Vaccines. 2020;5:98. [PubMed] [Google Scholar]

7. Blaney JE, Wirblich C, Papaneri AB, Johnson RF, Myers CJ, Juelich TL, Holbrook MR, Freiberg AN, Bernbaum JG, Jahrling PB, Paragas J, Schnell MJ. Inactivated or live-attenuated bivalent vaccines that confer protection against rabies and Ebola viruses. J Virol. 2011 Oct;85(20):10605-16. [PubMed] [Google Scholar] 